\title{
Characterization of C-S-H gels by pair distribution function analysis
}

\author{
A. Cuesta, A. Morales-Cantero, A.G. De la Torre, I. Santacruz, M.A.G. Aranda
}

Departamento de Química Inorgánica, Universidad de Málaga, 29071-Málaga (Spain), g_aranda@uma.es

Portland cement (PC) is the most manufactured world product. However, cement industry is one of the major contributors for greenhouse gas emissions. On average, for every ton of grey PC clinker, around $0.87 \mathrm{CO}_{2}$ tons are released into the atmosphere. Alternative cements showing similar performances to ordinary PC are needed. A recent work [1] commissioned by the United Nations Environment Program Sustainable Building and Climate Initiative has identified the use of supplementary cementitious materials (SCMs) as the most favourable approach for lowering $\mathrm{CO}_{2}$ emissions in the cement industry.

In order to develop more sustainable cements, the hydration products must be well understood which is far from straightforward. The hydration reactions of tricalcium silicate, $\mathrm{Ca}_{3} \mathrm{SiO}_{5}$ (main phase of $\mathrm{PC}$ ) consist of its dissolution, the formation of the nanocrystalline calcium-silicate-hydrate (C-S-H) gel, jointly with the crystallization of portlandite, $\mathrm{Ca}(\mathrm{OH})_{2}$ according to equation (1). C-S-H gel seems to be composed by defective nanocrystalline clinotobermorite, amorphous (a few layers thick) $\mathrm{Ca}(\mathrm{OH})_{2}$ and gel pore water [2].

$$
\begin{aligned}
& \mathrm{Ca}_{3} \mathrm{SiO}_{5}+5.2 \mathrm{H}_{2} \mathrm{O} \rightarrow 1.2 \mathrm{Ca}(\mathrm{OH})_{2}+1 / 9\left[\mathrm{Ca}_{11} \mathrm{Si}_{9} \mathrm{O}_{28}(\mathrm{OH})_{2} \cdot 8.5 \mathrm{H}_{2} \mathrm{O}\right] / / \\
& \text { Crystalline } 0.58\left[\mathrm{Ca}(\mathrm{OH})_{2}\right] / / 2.37 \mathrm{H}_{2} \mathrm{O}
\end{aligned}
$$

The main products of reaction (1) are: i) crystalline $\mathrm{Ca}(\mathrm{OH})_{2}$, ii) nanocrystalline tobermorite, and iii) amorphous $\mathrm{Ca}(\mathrm{OH})_{2}$. The calcium hydroxide formed in reaction (1) can be employed to yield additional secondary C-(A)-S-H through the pozzolanic reaction with SCMs. The analysis of nanocrystalline/amorphous phases in cement matrices which contain high amounts of crystalline phases is a challenging task. Pair distribution function (PDF) methodology in combination with synchrotron radiation is key to characterize cement pastes. PDF data can give insight about the atomic local structure of the non-crystalline components such as C-(A)-S-H gels.

This work focuses on the characterization of amorphous and nanocrystalline phases which are present in cement related pastes by total scattering PDF. We have studied a series of tricalcium silicate blended with silica fume at four months of hydration and dicalcium silicate samples hydrated at longer ages [3]. PDF data were collected at ALBA Synchrotron, beamline MSPD, see Figure 1. The changes in the local atomic order of the $\mathrm{C}-\mathrm{S}-\mathrm{H}$ gels formed from the hydration of pastes with silica fume by varying the overall $\mathrm{Ca} / \mathrm{Si}$ ratio were followed by differential PDF. It was found that the C-S-H gel formed by the pozzolanic reaction showed nearly the same local structure than the primary C-S-H gel. Furthermore, differential PDF pointed toward $\mathrm{Ca}(\mathrm{OH})_{2}$ excess having a local structure compatible with fewlayer thick nanoparticles stretched along the c-axis. Moreover, PDF data for commercial portlandite, nanoportlandite, synthetic C-S-H and synthetic C-A-S-H samples have been recently collected and they are being studied. The results will be compared and discussed.

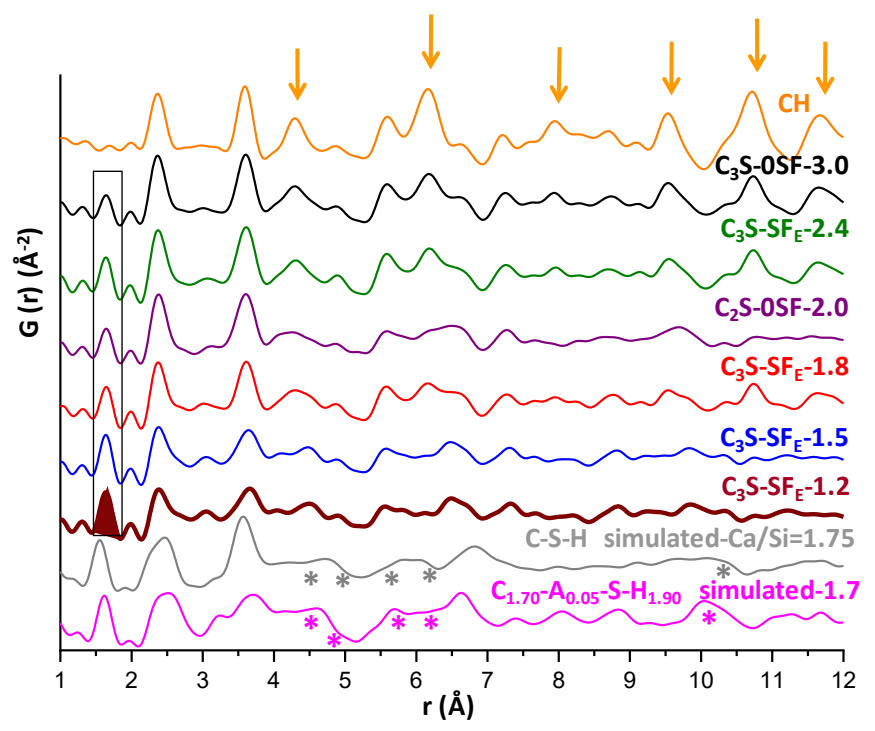

Figure 1. Synchrotron PDF patterns for the tricalcium silicate blended with silica fume pastes and dicalcium silicate paste. The experimental plot for commercial portlandite and the theoretical PDF patterns for C-S$\mathrm{H}$ and $\mathrm{C}-(\mathrm{A})-\mathrm{S}-\mathrm{H}$ are given as references [3].

[1] UN Environment, et al. (2018), Eco-efficient cements: Potential, economically viable solutions for a low-CO2, cement-based materials industry, Cem. Concr. Res. 114, 2-26.

[2] Cuesta, A., et al. (2018), Multiscale understanding of tricalcium silicate hydration reactions, Sci. Rep. 8, 8544.

[3] Cuesta, A., et al. (2021), Local structure and Ca/Si ratio in C-S-H gels from hydration of blends of tricalcium silicate and silica fume, Cem. Concr. Res. 143, 106405.

Keywords: pair distribution function, synchrotron radiation, nanostructure, amorphous material, pozzolanic reaction, SCMs

This research was funded by Ministry of Science (Spain), grant number PID2019-104378RJ-I00. 